\title{
BMJ Open Association of ambient particulate matter with heart failure incidence and all-cause readmissions in Tasmania: an observational study
}

\author{
Quan L Huynh, ${ }^{1}$ Christopher Leigh Blizzard, ${ }^{1}$ Thomas H Marwick, ${ }^{1,2}$ \\ Kazuaki Negishi ${ }^{1}$
}

To cite: Huynh QL, Blizzard CL, Marwick TH, et al. Association of ambient particulate matter with heart failure incidence and all-cause readmissions in Tasmania: an observational study. BMJ Open 2018;8:e21798. doi:10.1136/ bmjopen-2018-021798

- Prepublication history and additional material for this paper are available online. To view these files, please visit the journal online (http://dx.doi. org/10.1136/bmjopen-2018021798).

Received 18 January 2018 Revised 17 April 2018 Accepted 19 April 2018

Check for updates

${ }^{1}$ Menzies Institute for Medical Research, University of Tasmania, Hobart, Tasmania, Australia

${ }^{2}$ Department of Cardiology, Baker IDI Heart \& Diabetes Institute, Melbourne, Victoria, Australia

Correspondence to Dr Kazuaki Negishi;

kazuaki.negishi@utas.edu.au

\section{ABSTRACT}

Objectives We sought to investigate the relationship between air quality and heart failure (HF) incidence and rehospitalisation to elucidate whether there is a threshold in this relationship and whether this relationship differs for $\mathrm{HF}$ incidence and rehospitalisation.

Methods This retrospective observational study was performed in an Australian state-wide setting, where air pollution is mainly associated with wood-burning for winter heating. Data included all 1246 patients with a first-ever HF hospitalisation and their 3011 subsequent allcause readmissions during 2009-2012. Daily particulate matter $<2.5 \mu \mathrm{m}\left(\mathrm{PM}_{2.5}\right)$, temperature, relative humidity and influenza infection were recorded. Poisson regression was used, with adjustment for time trend, public and school holiday and day of week.

Results Tasmania has excellent air quality (median $\mathrm{PM}_{2.5}=2.9 \mu \mathrm{g} / \mathrm{m}^{3}$ (IQR: $\left.1.8-6.0\right)$ ). Greater HF incidences and readmissions occurred in winter than in other seasons $(\mathrm{p}<0.001) . \mathrm{PM}_{2.5}$ was detrimentally associated with $\mathrm{HF}$ incidence (risk ratio $(\mathrm{RR})=1.29(1.15-1.42))$ and weakly so with readmission $(\mathrm{RR}=1.07(1.02-1.17))$, with 1 day time lag. In multivariable analyses, $\mathrm{PM}_{2.5}$ significantly predicted HF incidence ( $R R=1.12(1.01-1.24))$ but not readmission ( $R R=0.96(0.89-1.04))$. HF incidence was similarly low when $\mathrm{PM}<4 \mu \mathrm{g} / \mathrm{m}^{3}$ and only started to rise when $\mathrm{PM}_{2.5} \geq 4 \mu \mathrm{g} / \mathrm{m}^{3}$. Stratified analyses showed that $\mathrm{PM}_{2.5}$ was associated with readmissions among patients not taking beta-blockers but not among those taking beta-blockers $\left(p_{\text {interaction }}=0.011\right)$.

Conclusions $\mathrm{PM}_{2.5}$ predicted HF incidence, independent of other environmental factors. A possible threshold of $\mathrm{PM}_{2.5}=4 \mu \mathrm{g} / \mathrm{m}^{3}$ is far below the daily Australian national standard of $25 \mu \mathrm{g} / \mathrm{m}^{3}$. Our data suggest that beta-blockers might play a role in preventing adverse association between air pollution and patients with HF.

\section{INTRODUCTION}

Heart failure (HF) is the leading cause of hospitalisation and rehospitalisation for adults aged over 65 years. ${ }^{12}$ Despite great improvements in medical therapy and management of risk factors for $\mathrm{HF}$, high readmission rates following an index $\mathrm{HF}$ admission continue
Strengths and limitations of this study

- This observational study was performed in Tasmania, one of the world's cleanest air areas with median $\mathrm{PM}_{2.5}$ level of $2.9 \mu \mathrm{g} / \mathrm{m}^{3}$. This has given us an opportunity to investigate the association of air pollution with heart failure (HF) within a range of air quality that was much wider than that of other previous studies of its kind.

- Our analyses were based on a wide range of environmental factors to determine the independent association of air pollution with HF.

- The separation of HF incidence and readmission enabled us to investigate the differences in their associations with air pollution and other environmental factors.

- This study is limited by the absence of available data on personal exposure to active and passive smoking, indoor temperature and other air pollutants.

- The adverse associations of air pollution on HF might have been underestimated in our study because our analyses were based on acute events associated with short-term exposures and did not take into account the effects of long-term exposure to air pollution.

to be a problem worldwide. ${ }^{3-5}$ In Australia, approximately 30000 patients are diagnosed with HF each year, and the costs for HF readmissions exceed $\$ 1$ billion annually. ${ }^{6}$ Finding and eliminating the triggers of acute cardiac decompensation will reduce the social and economic burden of HF.

The phenomenon of seasonal variations in HF has been well established. ${ }^{7-9}$ Although the underlying mechanisms are yet to be determined, observed increases in morbidity and mortality in cold weather may be partly due to increased ambient air pollution. ${ }^{10} 11$ A recent assessment of the global burden of disease ranked particulate matter air pollution as one of the leading causes of death and disability worldwide. ${ }^{12}$ 
A recent systematic review and meta-analysis has shown an adverse relationship between increases in ambient particulate matter and HF hospitalisation and death. ${ }^{13}$ However, it is unknown whether there is a threshold of particulate matter concentration in this relationship and whether this relationship may differ between HF incidence (defined as first-ever hospitalisation due to $\mathrm{HF}$ ) and all-cause readmission.

Tasmania has excellent air quality in comparison with other parts of Australia. While having very low median level of fine particulate matter $\left(\mathrm{PM}_{2.5}<3 \mu \mathrm{g} / \mathrm{m}^{3}\right)$ compared with regions with considered good air quality like Colorado, USA (median $\left.\mathrm{PM}_{2.5} 7.7 \mu \mathrm{g} / \mathrm{m}^{3}\right)^{13}$ or bad air quality like Beijing $\left(\mathrm{PM}_{2.5} 94 \pm 24 \mu \mathrm{g} / \mathrm{m}^{3}\right)$, there are days in Tasmania with high level of air pollution $\left(\mathrm{PM}_{2.5}\right.$ of up to $40 \mu \mathrm{g} / \mathrm{m}^{3}$ ). ${ }^{14}$ This very wide range of air quality provides a unique opportunity to investigate if there is a lower threshold for health outcomes associated with air pollution. The main cause of elevations in particulate matter in this setting is biomass smoke from wood heaters during winter and from bushfires and planned burns at other times of the year. ${ }^{15}$ In this retrospective cohort study, we measured air pollution and other environmental factors including temperature, relative humidity and influenza epidemics and investigated the associations of these factors with HF incidence and readmission. Patients may be exposed to different lifestyles, treatments and medications before and after the diagnosis of HF. By being able to separate HF incidence and readmission, we sought to determine the presence and mechanism of any differences in the relationship of these outcomes with environmental factors.

\section{METHODS}

\section{Study population}

This retrospective cohort study included all 1246 patients (median age 78 years, $51 \%$ male) who had their first-ever admission to a public hospital in Hobart and Launceston (Tasmania, Australia) due to HF between July 2009 and July 2012. These patients were identified by their coded diagnoses (International Classification of Diseases, Ninth Revision, Clinical Modification 402.x1, 404.x1, 404.x3, 428.x and 428.xx).

\section{Primary outcomes}

The primary outcomes of this study were daily count of HF incidence (defined as first hospitalisation due to HF) and subsequent all-cause readmissions that followed the index admission during the study period. Dates of hospitalisation were obtained from administrative data from the Clinical Informatics and Business Intelligence Unit of the Department of Health and Human Services of Tasmania.

\section{Patient and public involvement}

Patients or public were not involved in this study.

\section{Environmental data}

The Australian state of Tasmania is an island to the south of the continent, characterised by a colder and wetter climate, and cleaner air quality, than the rest of the Australia. In this southern hemisphere, winter is defined as June-August, spring as September-November, summer as December-February and autumn as March to May. ${ }^{16}$ Hobart (population 247461 in 2011) and Launceston (population 137561 in 2011) are the two largest cities of Tasmania (total population 495354 in 2011) and provide residence for nearly $80 \%$ of the whole state's population. ${ }^{17}$ There is only one public hospital in each of Hobart (the Royal Hobart Hospital) and Launceston (the Launceston General Hospital). Air pollution in Hobart and Launceston was estimated by hourly concentrations of particulate matter less than $2.5 \mu \mathrm{m}$ in diameter $\left(\mathrm{PM}_{2.5}\right)$ with gravimetric sampling methods. ${ }^{18}$ Simultaneous monitoring of air quality was previously conducted at multiple sites and showed highly correlated measurements. ${ }^{18}$ After these findings, a representative site was selected for ongoing monitoring air quality in each city all year. Data on daily temperature and relative humidity were from the Bureau of Meteorology. ${ }^{19}$ Daily count of positive laboratory tests for influenza in Tasmania was also recorded.

\section{Demographic and clinical data}

Additional demographic and clinical data were collected from medical records of the first HF admission. ${ }^{20}$

\section{Statistical analyses}

Cumulative incidence of HF was estimated by taking the ratio of new HF cases to the total population of Hobart and Launceston. We calculated daily concentration of $\mathrm{PM}_{2.5}$ by averaging their hourly measurements from each day, for Hobart and Launceston separately. Daily mean temperature and relative humidity were calculated by averaging maximum and minimum temperature and relative humidity of each day. These measurements were then weighted based on the ratio of population in the two cities to derive an average value to be used in analysis. The rolling sum of positive influenza tests during the last 7 days (including the current day) was calculated, and the 90th percentile cut-off was used to define influenza epidemic. Pearson correlation was used to estimate the strength of the relationships among these environmental factors. Because of the nature of our primary outcomes (count variables), Poisson regression was used to estimate the associations of air pollution and other environmental factors with the primary outcomes of this study. These associations were estimated for the same day $\left(\operatorname{lag}_{0}\right)$ and up to 5 days before the outcome ( $\operatorname{lag}_{1}$ to $\left.\operatorname{lag}_{5}\right)$ and for the previous 3 days moving average $\left(\operatorname{lag}_{1-3}\right)$. Binary variables were created for weekday and weekend, school holidays and public holidays for adjustment. A smooth function of calendar time (natural cubic splines) with $7 \mathrm{df}$ per year was used to adjust for seasonal patterns and any other time-dependent influences on HF admissions (including long-term trends due to changes in medical practice). 
Table 1 Data on heart failure incidence and readmission, and environmental factors in Hobart and Launceston (Australia) in 2009-2012 (1096 days)

\begin{tabular}{lc}
\hline Heart failure hospitalisations & \\
\hline Incidence (counts/day) & $1(0-2)$ \\
\hline All-cause readmission (counts/day) & $3(2-4)$ \\
\hline Male & $632(51)$ \\
\hline Age at index admission (years) & $80(72-86)$ \\
\hline NYHA classification before discharge & \\
\hline Class I & $174(14)$ \\
Class II & $449(36)$ \\
\hline Class III & $424(34)$ \\
\hline Class IV & $199(16)$ \\
Beta-blocker use & $660(53)$ \\
ACEi/ARB use & $909(73)$ \\
\hline Diuretic use & $1159(93)$ \\
\hline Aldosterone use & $386(27)$ \\
\hline Digoxin use & $274(22)$ \\
\hline Antiarrhythmic medication use & $100(8)$ \\
\hline
\end{tabular}

\section{Environmental factors}

\begin{tabular}{lc}
\hline Daily air concentration of $\mathrm{PM}_{2.5}\left(\mu \mathrm{g} / \mathrm{m}^{3}\right)$ & $2.9(1.8-6.1)$ \\
\hline Mean daily temperature $\left({ }^{\circ} \mathrm{C}\right)$ & $13.2(9.9-16.7)$ \\
Min daily temperature $\left({ }^{\circ} \mathrm{C}\right)$ & $8.2(4.9-11.7)$ \\
Max daily temperature $\left({ }^{\circ} \mathrm{C}\right)$ & $18.0(14.6-22.2)$ \\
Daily relative humidity $(\%)$ & $74(66-82)$ \\
\hline
\end{tabular}

Data are reported as median (IQR) or $\mathrm{n}(\%)$.

ACEI, ACE inhibitor; ARB, angiotensin receptor blocker; NYHA, New York Heart Association.

Because the relationship of temperature with HF admissions appeared to be linear in our study (as shown in Results section, possibly due to the cool climate nature of Tasmania), we fitted a linear term for temperature in our analysis.

\section{RESULTS}

\section{Heart failure}

Data on HF hospitalisations are shown in table 1.

Patients from Hobart and Launceston had very similar socioeconomic status (Index of Relative Socioeconomic Advantage and Disadvantage: $912 \pm 105$ vs $914 \pm 90$, $\mathrm{p}=0.73$ ). Only a small proportion of patients from both cities were from remote/very remote areas (Hobart: $2 \%$ and Launceston: $1 \%$ ).

There were 1246 HF incidences (median: 1 new case/ day). The estimated cumulative incidence of HF was 3.2 per 1000 persons over the study period. After the first HF hospitalisation, there were 3011 subsequent all-cause readmissions (with $35 \%$ being HF-specific readmissions) during the study period. The majority of patients $(70 \%)$ were classified as New York Heart Association (NYHA) class II/III. Diuretics were the most commonly used

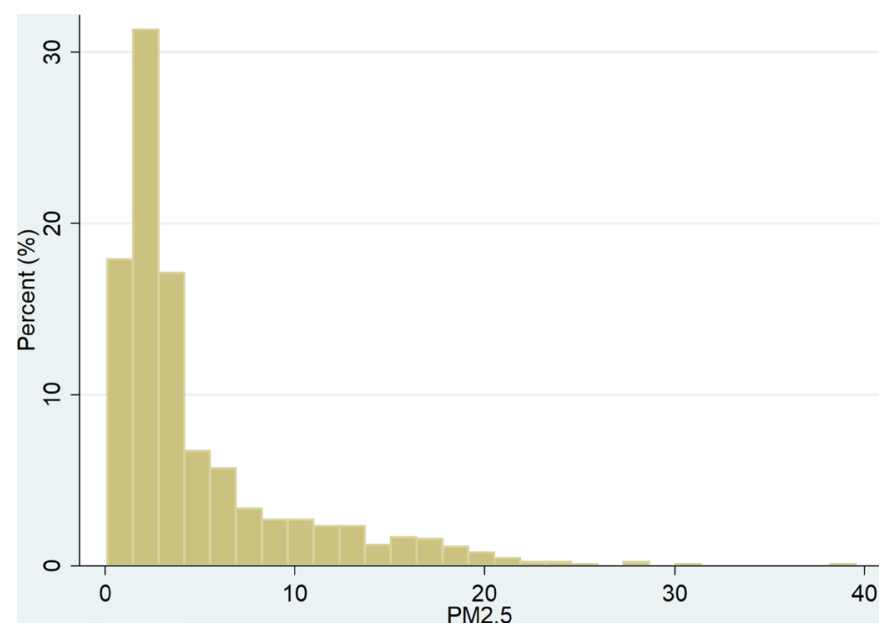

Figure 1 Distribution of $\mathrm{PM}_{2.5}$.

medication, followed by ACE inhibitors (ACEis) or angiotensin receptor blockers (ARBs).

\section{Environmental factors}

The distribution of $\mathrm{PM}_{2.5}$ is shown in figure 1.

Median levels of $\mathrm{PM}_{2.5}$, temperature and relative humidity are shown in table 1 . The correlations among these measurements, which are moderate at best, are shown in table 2.

\section{Seasonal variations of $\mathrm{HF}$}

The seasonal variations of HF are illustrated in figure 2. The incidence of new cases of HF peaked during winter months (June-August). This phenomenon also aligned well with the peaks in $\mathrm{PM}_{2.5}$ and relative humidity and with the lowest levels of temperature. Figure 3 further demonstrated this seasonal variation in HF by showing significant trends in HF incidence and readmissions that both peaked during winter and reduced during other seasons.

\section{Associations with primary outcomes}

Table 3 shows univariable associations of air pollution and other environmental factors with HF incidence and all-cause readmission.

While air pollution was adversely associated with HF incidence, it was not or very weakly associated with readmission. Temperature, relative humidity and influenza epidemic periods, however, were associated with both HF incidence and all-cause readmission. These findings were consistent with those of HF-specific readmissions (online supplementary table 1). It is consistent for all

\begin{tabular}{lccc|}
\hline Table 2 & Correlations among the environmental factors \\
& $\mathbf{P M}_{2.5}$ & Temperature & $\begin{array}{l}\text { Relative } \\
\text { humidity }\end{array}$ \\
\hline $\mathrm{PM}_{2.5}$ & 1.00 & & \\
Temperature & $-0.38^{*}$ & 1.00 \\
Humidity & $0.35^{*}$ & $-0.23^{*}$ & 1.00 \\
\hline
\end{tabular}

${ }^{*} \mathrm{P}<0.001$. 


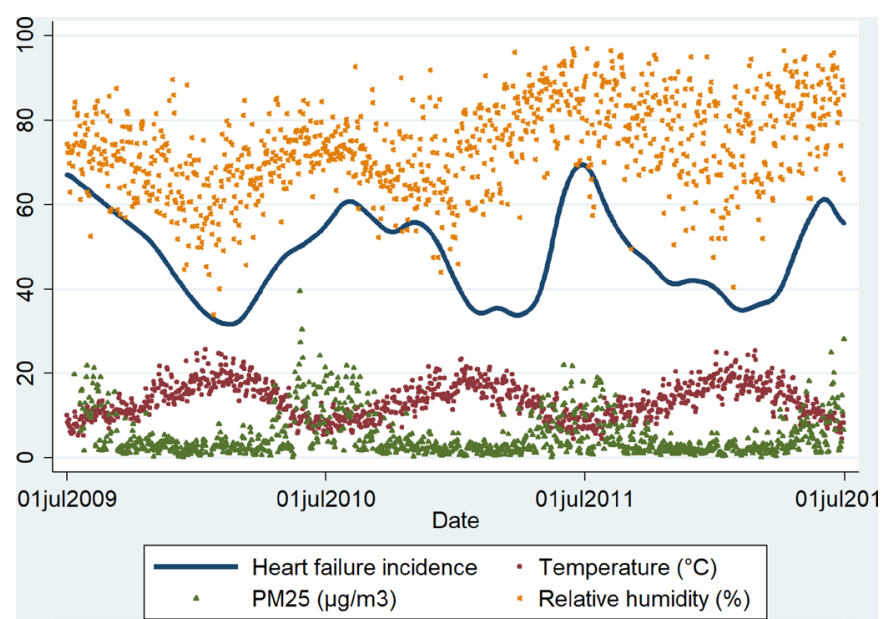

Figure 2 Seasonal variations of heart failure and environmental factors.

environmental factors $\left(\mathrm{PM}_{2.5}\right.$, temperature and relative humidity) that their associations with $\mathrm{HF}$ incidence were either strongest or second strongest with three lagging days average. This suggests that the environmental effect on HF is through continuous exposure, and for consistency, this three lagging day average $\left(\operatorname{lag}_{1-3}\right)$ variables will be used for multivariable analysis. The associations between environmental factors and HF are also illustrated in figures 4-6, demonstrating dose-response relationships.

Table 4 shows multivariable associations of air pollution and other environmental factors with the outcomes.

Among the environmental factors, only $\mathrm{PM}_{2.5}$ and temperature remained as significant predictors of $\mathrm{HF}$ incidence. However, while temperature, relative humidity and presence of influenza epidemic were significantly associated with readmissions, $\mathrm{PM}_{2.5}$ did not predict readmissions among HF patients.

\section{Possible threshold of $\mathrm{PM}_{2.5}$ in predicting HF incidence}

The relationship of $\mathrm{PM}_{2.5}$ with $\mathrm{HF}$ incidence count per day is shown in figure 4 . Although there was a highly

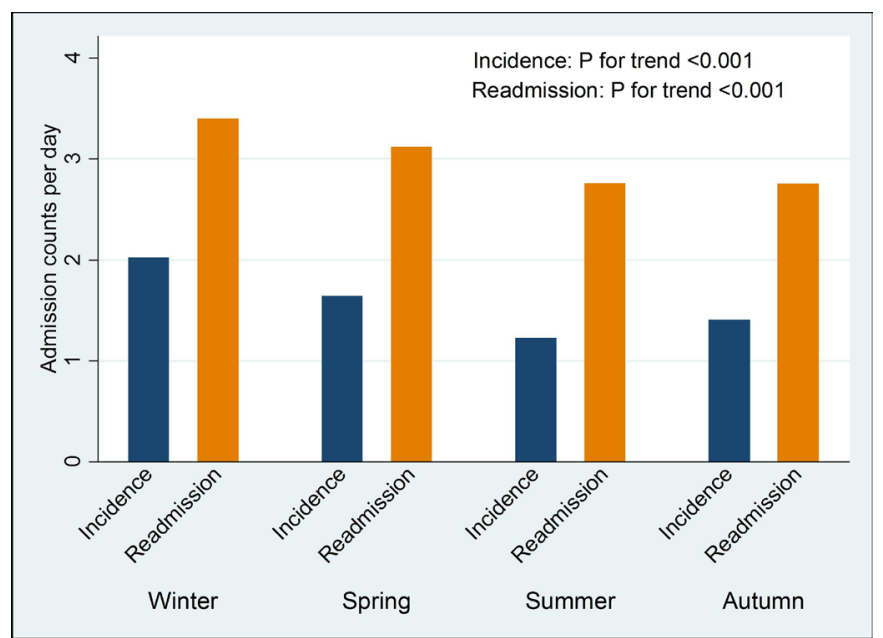

Figure 3 Heart failure incidence and readmission by seasons. significant trend of increasing HF incidence throughout the whole range of $\mathrm{PM}_{2.5}$ included in this study, the level of HF incidence count per day appeared to increase when $\mathrm{PM}_{2.5}$ reached the fourth quintile. This finding suggests that there might be a threshold in the relationship of $\mathrm{PM}_{2.5}$ with $\mathrm{HF}$ incidence. Therefore, we further investigated this relationship by breaking the whole range of $\mathrm{PM}_{2.5}$ into nine groups each of which contained approximately 100 days of our study period (figure 7). The $\mathrm{HF}$ incidence count per day started to rise when $\mathrm{PM}_{2.5}$ was beyond $4 \mu \mathrm{m} / \mathrm{m}^{3}$. While the relationship between $\mathrm{PM}_{2.5}$ and HF incidence was null when $\mathrm{PM}_{2.5}<4 \mu \mathrm{m} / \mathrm{m}^{3}$ $(\mathrm{RR}=0.99$ (95\% CI 0.92 to 1.07$)$ ), it was significantly positive when $\mathrm{PM}_{2.5} \geq 4 \mu \mathrm{m} / \mathrm{m}^{3}$ (RR=1.20 (95\% CI 1.07 to 1.34)). This was consistent with no correlation between $\mathrm{PM}_{2.5}$ and HF incidence when $\mathrm{PM}_{2.5}<4 \mu \mathrm{m} / \mathrm{m}^{3}(\beta=-0.01$ $(-0.07$ to 0.05$), \mathrm{p}=0.48)$ and a positive correlation when $\mathrm{PM}_{2.5} \geq 4 \mu \mathrm{m} / \mathrm{m}^{3} \quad(\beta=0.17$ (0.07 to 0.35), $\mathrm{p}=0.008)$. These findings are controlled for temperature. Consistent findings were found when the $\mathrm{PM}_{2.5}$ range was broken by deciles (online supplementary figure 1). HF incidence count per day started to rise when $\mathrm{PM}_{2.5}$ was beyond the seventh decile (median $4.1 \mu \mathrm{m} / \mathrm{m}^{3}$ ). Using any threshold greater than $4 \mu \mathrm{m} / \mathrm{m}^{3}$ would result in a positive association between $\mathrm{PM}_{2.5}$ and $\mathrm{HF}$ incidence when $\mathrm{PM}_{2.5}$ below the new threshold (not shown).

\section{Possible protective effects of HF medication against air pollution}

The concentration of $\mathrm{PM}_{2.5}$ was adversely associated with HF incidence but not with readmission. We further investigated whether HF medications prescribed after the confirmed diagnosis of HF may play a role in protecting patients against the adverse association with air pollution. We classified patients by whether they were prescribed common HF medications (beta-blockers, ACEi/ARB and diuretics) after their first admission with HF. For ACEi/ $\mathrm{ARB}$ and diuretics, there was no difference in the association of $\mathrm{PM}_{2.5}$ with readmission count per day among patients who took these medications (ACEi/ARB: $\beta=0.04$ ( -0.02 to 0.08$), p=0.15$, diuretics: $\beta=0.05$ ( -0.01 to 0.11 ), $\mathrm{p}=0.084)$ and those who did not (ACEi/ARB: $\beta=0.02$ ( -0.01 to 0.03$), p=0.27$, diuretics: $\beta=0.04$ ( -0.02 to 0.09$)$, $\mathrm{p}=0.11$ ). However, while $\mathrm{PM}_{2.5}$ was not associated with readmission count per day among patients who took betablockers (figure $8, \beta=-0.01$ ( -0.07 to 0.06 ), $\mathrm{p}=0.89$ ), $\mathrm{PM}_{2.5}$ was positively associated with readmission count per day among patients who did not take beta-blockers (figure 8, $\beta=0.14$ (0.05 to 0.23), $p=0.002$ ). There was a significant interaction between beta-blockers use and $\mathrm{PM}_{2.5}$ in their association with HF readmission $(p=0.011)$. When restricting the analysis to HF-specific readmissions only, the association of $\mathrm{PM}_{2.5}$ with readmission count per day was also stronger among patients who did not take betablockers $(\beta=0.09$ ( 0.01 to 0.19$), p=0.01)$ than that among patients who took beta-blockers $(\beta=0.03$ ( -0.02 to 0.07$)$, $\mathrm{p}=0.34)$. 
Table 3 Univariable Poisson regression of environmental factors with heart failure incidence and readmissions

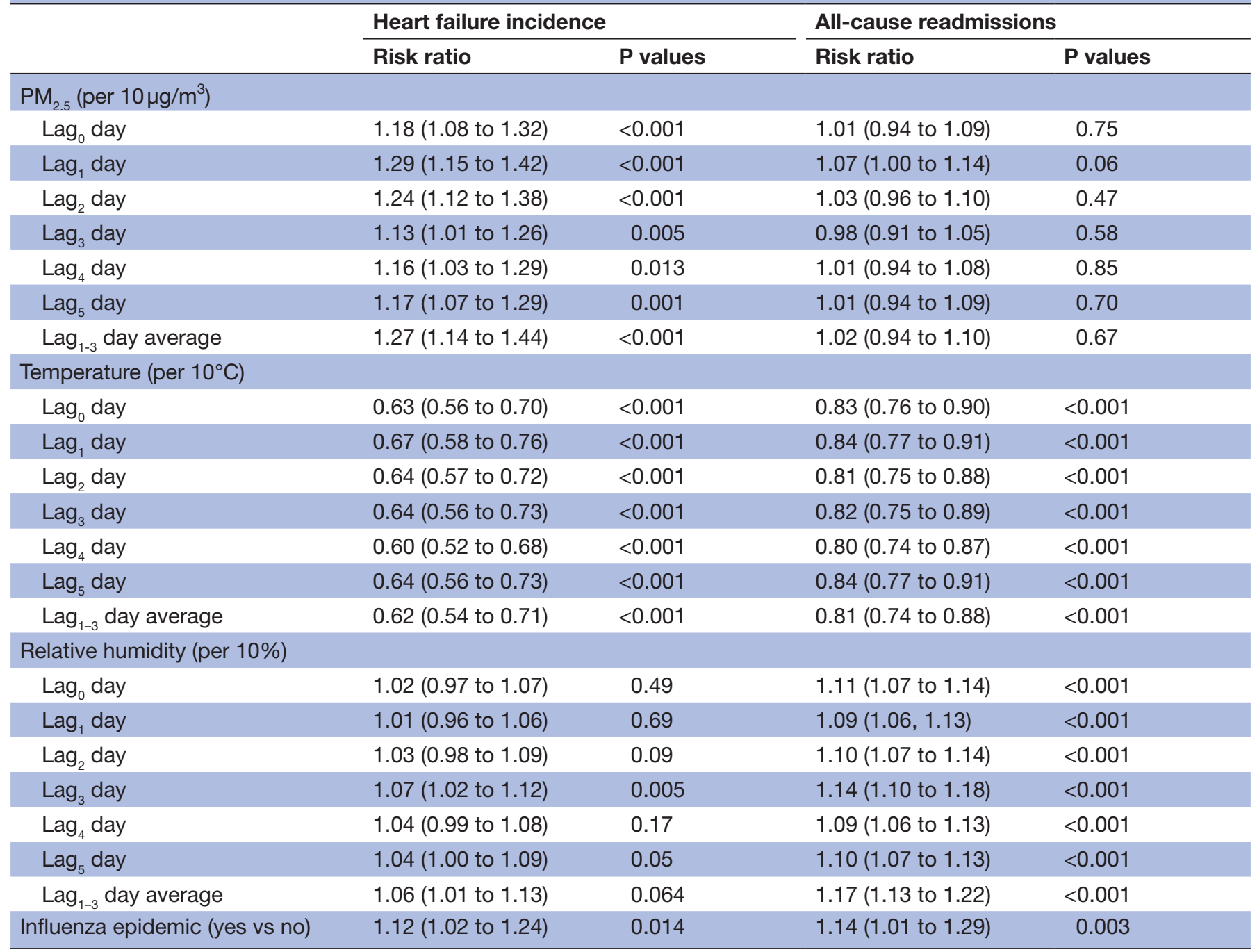

\section{DISCUSSION}

This study investigated the relationships of particulate air pollution and other environmental factors with $\mathrm{HF}$ incidence and all-cause readmission and provided several

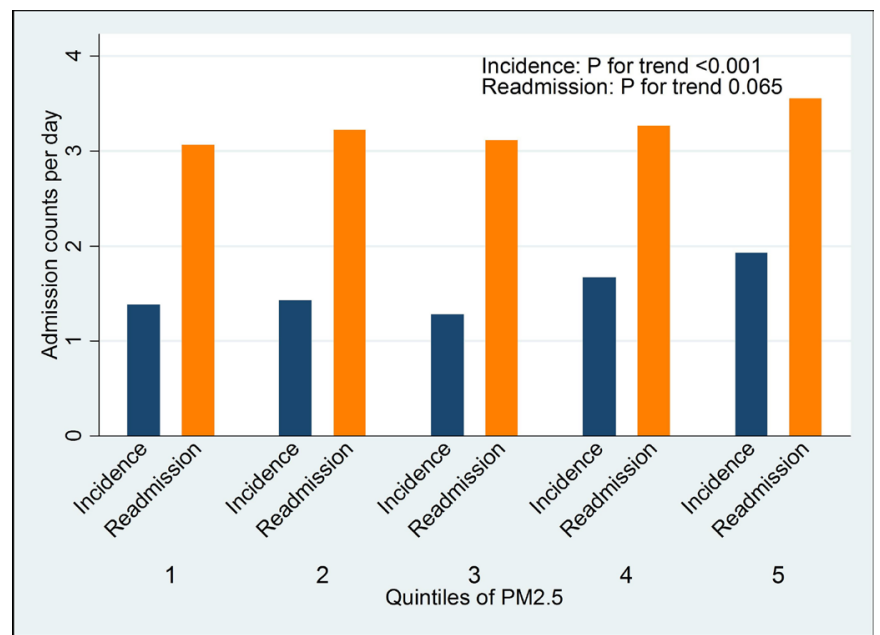

Figure 4 Associations of quintile of $\mathrm{PM}_{2.5}$ with heart failure incidence and readmission. important and novel findings. Acute exposure to ambient particulate matter is adversely associated with increased HF incidence after adjusting for other environmental factors, even in regions with very low air pollution such

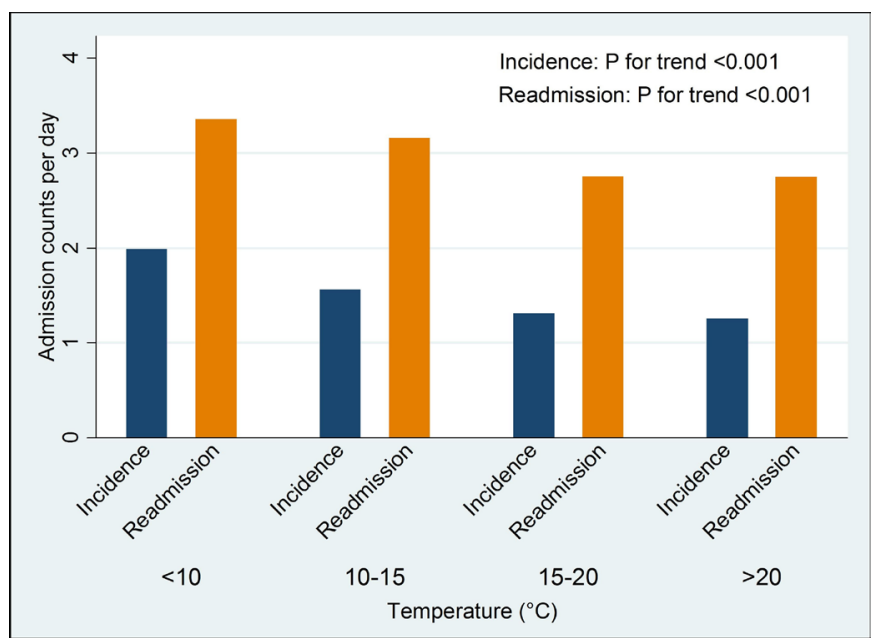

Figure 5 Associations of temperature with heart failure incidence and readmission. 


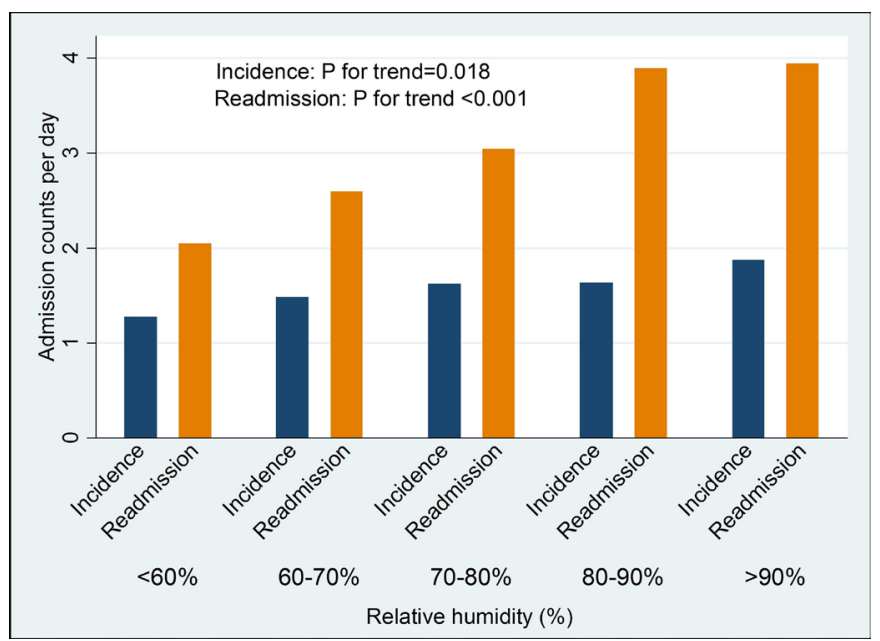

Figure 6 Associations of relative humidity with heart failure incidence and readmission.

as Tasmania. More importantly, the relationship between $\mathrm{PM}_{2.5}$ and $\mathrm{HF}$ incidence appeared to have a threshold of approximately $4 \mu \mathrm{g} / \mathrm{m}^{3}$, which is far below the daily Australian and WHO standard of $\mathrm{PM}_{2.5}$ of $25 \mu \mathrm{g} / \mathrm{m}^{3}$. While temperature and relative humidity were associated with readmission, air pollution was very weakly associated with all-cause readmission among patients with HF. This might be partly due to protective effects of beta-blockers.

\section{Air pollution and HF}

Although the mechanisms underlying the relationship between particulate air pollution and HF are not well understood, possible causal pathways through increased oxidative stress and inflammation have been proposed.$^{21-23}$ These pathways involve adverse effects on both the systemic arterial and venous circulation and lead to an increase in systemic blood pressure, myocardial ischaemia, vasoconstriction, atherosclerosis and arrhythmia. All these factors contribute to the exacerbation of HF. The positive association of air pollution with HF incidence shown in our study suggests that air pollution also plays a role in the development of HF.

To the best of our knowledge, this is the first time a threshold of $\mathrm{PM}_{2.5}$ has been detected for its association with HF. The very low threshold of $\mathrm{PM}_{2.5}$ observed in our study (approximately $4 \mu \mathrm{g} / \mathrm{m}^{3}$ ) explains the persistent adverse effects of air pollution when $\mathrm{PM}_{2.5}$ levels were lower than the Australian and WHO standard of $25 \mu \mathrm{g} /$

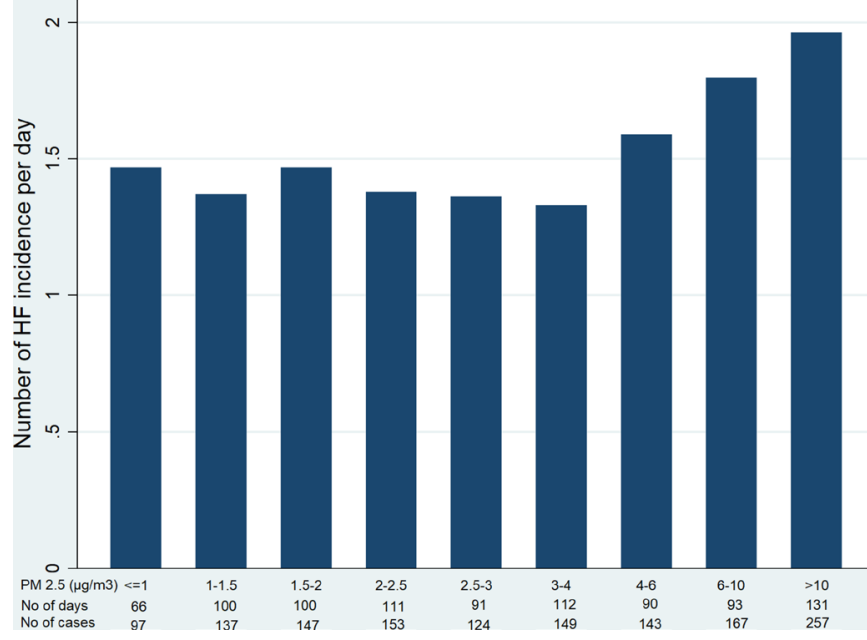

Figure 7 Possible threshold of $\mathrm{PM}_{2.5}$ with heart failure (HF) incidence.

$\mathrm{m}^{3}{ }^{3425}$ This is even lower than the target concentration of $5.8 \mathrm{\mu g} / \mathrm{m}^{3}$ used in the recent meta-analysis, ${ }^{13}$ which was the lowest concentration observed in 116 cities in the USA during 1999-2000 $\mathrm{PM}_{2.5}$ collection period. ${ }^{26} 27$ The finding that $\mathrm{PM}_{2.5}$ was linearly associated with $\mathrm{HF}$ when beyond the threshold is consistent with that found in other studies ${ }^{13}$ and suggests that any effort to improve air quality is beneficial if a level of $\mathrm{PM}_{2.5}$ as low as $4 \mu \mathrm{g} / \mathrm{m}^{3}$ is too difficult to achieve. Our findings link well to those in previous studies and together they form a complete picture of the relationship between $\mathrm{PM}_{2.5}$ and HF.

\section{Possible protective effects of beta-blockers}

$\mathrm{PM}_{2.5}$ was associated with increased HF incidence after accounting for other environmental factors but was not associated with HF specific or all-cause readmission. Although there were no interactions of ACEi/ARB or diuretic use on the relationship between $\mathrm{PM}_{2.5}$ level and HF readmission, there was a significant interaction of beta-blocker use with this relationship. This difference in the relationship of $\mathrm{PM}_{2.5}$ with $\mathrm{HF}$ incidence and $\mathrm{HF}$ specific or all-cause readmission may be partly due to the protective effects of beta-blockers. Because the mechanisms underlying the association between $\mathrm{PM}_{2.5}$ and $\mathrm{HF}$ are not fully understood, how the use of beta-blockers may contribute to this relationship is further unclear. However, there are three possible mechanisms: (1) betablockers are known to influence the autonomic nervous

Table 4 Multivariable Poisson regression of environmental factors with heart failure incidence and readmissions

\begin{tabular}{|c|c|c|c|c|}
\hline & \multicolumn{2}{|c|}{ Heart failure incidence } & \multicolumn{2}{|c|}{ All-cause readmissions } \\
\hline & Risk ratio & $P$ values & Risk ratio & $P$ values \\
\hline $\mathrm{PM}_{2.5} \operatorname{lag}_{1-3}$ day $\left(\right.$ per $\left.10 \mu \mathrm{g} / \mathrm{m}^{3}\right)$ & $1.10(1.01-1.22)$ & 0.039 & $0.96(0.89-1.04)$ & 0.44 \\
\hline Relative humidity $\operatorname{lag}_{1-3}$ day (per $10 \%$ ) & $0.98(0.92-1.05)$ & 0.56 & $1.10(1.05-1.15)$ & 0.001 \\
\hline Influenza epidemic (yes vs no) & $1.01(0.80-1.21)$ & 0.45 & $1.20(1.06-1.38)$ & 0.005 \\
\hline
\end{tabular}

Further adjusted for weekday and weekend, school and public holiday and time trend. 


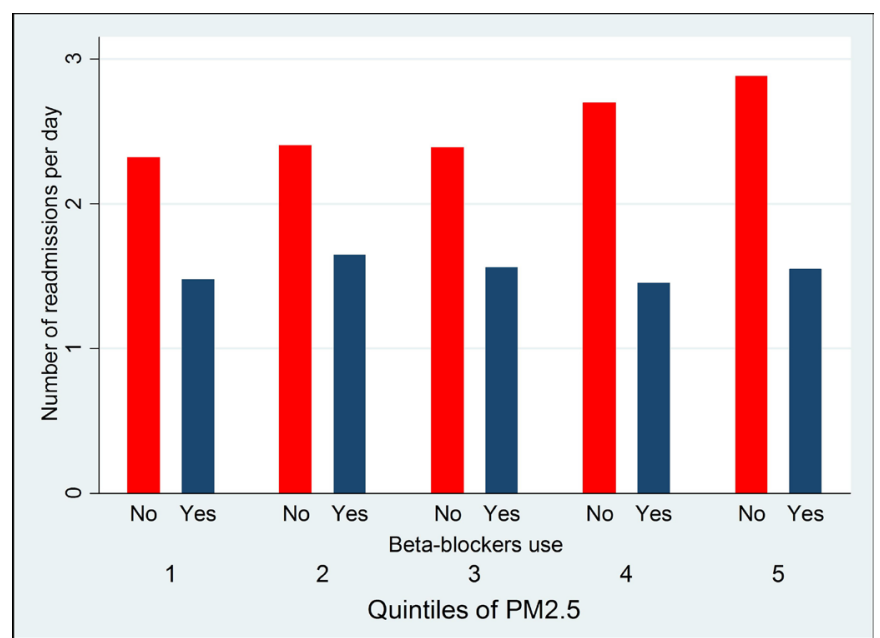

Figure 8 Possible protective effects of beta-blockers.

system, which is one of the proposed causal pathways between $\mathrm{PM}_{2.5}$ and HF. Specifically, previous studies have shown that the use of beta-blockers modifies the effect of $\mathrm{PM}_{2.5}$ on heart rate variability ${ }^{28-30}$-a reliable marker of autonomic activity and a predictor of increased risk for cardiovascular morbidity and mortality. ${ }^{31}{ }^{32}$ (2) It is also reported that beta-blockers provide anti-inflammatory benefits in chronic $\mathrm{HF}$ by lowering the circulating level of tumour necrosis factor-alpha and increasing the levels of anti-inflammatory cytokines. ${ }^{33}$ (3) Furthermore, a protective effect of beta-blockers on exercise-induced ST depression after exposure to $\mathrm{PM}_{2.5}$ was also reported. ${ }^{34}$

One could argue that the patients without beta-blocker could not have tolerated taking them because they were too sick. Indeed, patients who were prescribed betablockers in our study were at younger age at their first admission and had slightly lower mean NYHA class, Charlson comorbidity index, heart rate and respiratory rate (online supplementary table 2), but there was no association with socioeconomic factors. However, patients who were prescribed ACEi/ARB also had similar characteristics (online supplementary table 3). Therefore, the protective effects of beta-blockers use (but not of ACEi/ ARB) that were observed in our study were likely not fully explained by these discrepancies. However, because patients with HF usually have respiratory comorbidities such as asthma or chronic obstructive pulmonary disease that may contraindicate the use of beta-blockers, we could not completely exclude the possibility of a residual confounding caused by these conditions in our study. Thus, further studies on this are needed.

\section{Differences between HF incidence and readmission}

Apart from the differences in the associations with air pollution, HF incidence and readmission were also different in their associations with relative humidity and influenza infection epidemic. While these environmental factors were not independently associated with HF incidence, they were independently and adversely associated with readmission. This may be due to increased vulnerability once patients have developed $\mathrm{HF}$, and a mild trigger might also lead to exacerbation of $\mathrm{HF}$, or this may be due to the attenuation of significant effect of particulate air pollution resulted from beta-blocker use. The consistent findings for HF-specific readmissions and all-cause readmissions in our study support this speculation.

\section{Strengths and limitations}

This study has some particular strengths. The $\mathrm{PM}_{2.5}$ median level of $2.9 \mu \mathrm{g} / \mathrm{m}^{3}$ is a unique aspect of the study, as Tasmania has some of the world's cleanest air. This has given us an opportunity to investigate the association of air pollution with HF within a range of air quality that was much wider than that of other previous studies of its kind. Second, our analyses were based on a wide range of environmental factors to determine the association of air pollution with HF. Third, the separation of HF incidence and readmission enabled us to investigate the differences in their associations with air pollution and other environmental factors.

This study is limited by the absence of available data on personal exposure to active and passive smoking, indoor temperature and other air pollutants (such as nitrogen dioxide, ozone and sulfur dioxide). Second, the adverse association between air pollution and HF might have been underestimated in our study, because our analyses were based on acute events associated with short-term exposures and did not take into account the effects of long-term exposure to air pollution. Third, our study did not take into account the duration, dosage and adherence of beta-blocker use and factors (including severity of $\mathrm{HF}$ ) that may influence the use of beta-blockers. Future studies are therefore required to confirm this relationship and further explore if the benefit of betablockers use in this context is dose-response. Because most HF patients with reduced ejection fraction would have been prescribed beta-blockers if not contraindicated, it is important to confirm our findings for $\mathrm{HF}$ patients with preserved ejection fraction. Finally, due to the retrospective nature of our study, we only had echocardiography data on a subset of 451 patients (online supplementary tables 2 and 3) and were unable to investigate this matter. Further studies are therefore needed for this investigation.

\section{CONCLUSIONS}

In summary, our findings confirm the seasonal variations of $\mathrm{HF}$ and demonstrate an adverse relationship of air pollution with $\mathrm{HF}$ even in a very low range of $\mathrm{PM}_{2.5}$. For the first time, a possible threshold of $\mathrm{PM}_{2.5}=4 \mu \mathrm{g} /$ $\mathrm{m}^{3}$ has been detected in our study. This finding should encourage us to keep improving the air quality to reduce the burden of HF. Further studies are required to confirm the possible protective effects of beta-blockers against air pollution. 
Acknowledgements The authors would like to thank Dr Fay H Johnston for her intellectual advice and collecting meteorological data.

Contributors KN conceived the research questions and designed the study. QLH conducted data collection, performed analysis and drafted a manuscript. CLB contributed to statistical analyses and interpretation. All authors contributed to data interpretation and revisions of the manuscript critically for important intellectual content. KN, QLH and THM obtained funding. All authors approved the final version of the submitted manuscript and agreed to be accountable for all aspects of the work.

Funding Supported in part by a partnership grant from the National Health and Medical Research Foundation (Canberra), Tasmania Medicare Local (Hobart), Department of Health and Human Services (Hobart) and National Heart Foundation of Australia (Canberra).

Competing interests None declared.

Patient consent Not required.

Ethics approval The study protocol was approved by Human Research Ethics Committee Tasmania (№. H0014931).

Provenance and peer review Not commissioned; externally peer reviewed.

Data sharing statement The anonymised original data can be shared upon the ethical approval.

Open Access This is an Open Access article distributed in accordance with the Creative Commons Attribution Non Commercial (CC BY-NC 4.0) license, which permits others to distribute, remix, adapt, build upon this work non-commercially, and license their derivative works on different terms, provided the original work is properly cited and the use is non-commercial. See: http://creativecommons.org/ licenses/by-nc/4.0/

(C) Article author(s) (or their employer(s) unless otherwise stated in the text of the article) 2018. All rights reserved. No commercial use is permitted unless otherwise expressly granted.

\section{REFERENCES}

1. Jencks SF, Williams MV, Coleman EA. Rehospitalizations among patients in the Medicare fee-for-service program. N Engl J Med 2009;360:1418-28.

2. Mozaffarian D, Benjamin EJ, Go AS, et al. Heart disease and stroke statistics--2015 update: a report from the American Heart Association. Circulation 2015;131:e29-322.

3. Eapen ZJ, Liang L, Fonarow GC, et al. Validated, electronic health record deployable prediction models for assessing patient risk of 30-day rehospitalization and mortality in older heart failure patients. JACC Heart Fail 2013;1:245-51.

4. Blair JE, Zannad F, Konstam MA, et al. Continental differences in clinical characteristics, management, and outcomes in patients hospitalized with worsening heart failure results from the EVEREST (Efficacy of Vasopressin Antagonism in Heart Failure: Outcome Study with Tolvaptan) program. J Am Coll Cardiol 2008;52:1640-8.

5. Vivo RP, Krim SR, Liang L, et al. Short- and long-term rehospitalization and mortality for heart failure in 4 racial/ethnic populations. J Am Heart Assoc 2014;3:e001134.

6. National Heart Foundation of Australia. A systematic approach to chronic heart failure care: a consensus statement. Melbourne: National Heart Foundation of Australia, 2013.

7. Boulay F, Berthier F, Sisteron O, et al. Seasonal variation in chronic heart failure hospitalizations and mortality in France. Circulation 1999;100:280-6.

8. Stewart S, Mclntyre K, Capewell S, et al. Heart failure in a cold climate. Seasonal variation in heart failure-related morbidity and mortality. J Am Coll Cardiol 2002;39:760-6.

9. Inglis SC, Clark RA, Shakib S, et al. Hot summers and heart failure: seasonal variations in morbidity and mortality in Australian heart failure patients (1994-2005). Eur J Heart Fail 2008;10:540-9.

10. Newby DE, Mannucci PM, Tell GS, et al. Expert position paper on air pollution and cardiovascular disease. Eur Heart J 2015;36:83-93.

11. Atkinson RW, Carey IM, Kent AJ, et al. Long-term exposure to outdoor air pollution and incidence of cardiovascular diseases. Epidemiology 2013;24:44-53.
12. Lim SS, Vos T, Flaxman AD, et al. A comparative risk assessment of burden of disease and injury attributable to 67 risk factors and risk factor clusters in 21 regions, 1990-2010: a systematic analysis for the Global Burden of Disease Study 2010. Lancet 2012;380:2224-60.

13. Shah AS, Langrish JP, Nair H, et al. Global association of air pollution and heart failure: a systematic review and meta-analysis. Lancet 2013;382:1039-48.

14. He MZ, Zeng X, Zhang K, et al. Fine Particulate Matter Concentrations in Urban Chinese Cities, 2005-2016: A Systematic Review. Int J Environ Res Public Health 2017;14:E191.

15. Tasmania Air Monitoring Report. Compliance with the National Environment Protection Measure (Ambient Air Quality) for 2013. Tasmania: Environment Protection Authority, 2014.

16. Climate Glossary. Commonwealth of Australia, Bureau of Meteorology. http://www.bom.gov.au/climate/glossary/seasons.shtml (cited 20 Mar 2014).

17. Health Indicators Tasmania 2013. Epidemiology unit, population health. Tasmania: Department of Health and Human Services, 2013.

18. Lyons L. Air pollution, environmental and respiratory diseases, Launceston and Upper Tamar Valley Tasmania. Tasmania: Launceston City Council, 1996.

19. National Climate Centre of the Bureau of Meteorology. Daily or three hourly weather data for bureau of meteorology stations. Melbourne: Bureau of Meteorology, 2010.

20. Huynh QL, Saito M, Blizzard CL, et al. Roles of nonclinical and clinical data in prediction of 30-day rehospitalization or death among heart failure patients. J Card Fail 2015;21:374-81.

21. Mills NL, Donaldson K, Hadoke PW, et al. Adverse cardiovascular effects of air pollution. Nat Clin Pract Cardiovasc Med 2009;6:36-44.

22. Forastiere F, Agabiti N. Assessing the link between air pollution and heart failure. Lancet 2013;382:1008-10.

23. Brook RD, Rajagopalan S, Pope CA, et al. Particulate matter air pollution and cardiovascular disease: An update to the scientific statement from the American Heart Association. Circulation 2010;121:2331-78.

24. Beelen R, Raaschou-Nielsen O, Stafoggia M, et al. Effects of longterm exposure to air pollution on natural-cause mortality: an analysis of 22 European cohorts within the multicentre ESCAPE project. Lancet 2014;383:785-95.

25. Gan WQ, Davies HW, Koehoorn M, et al. Association of long-term exposure to community noise and traffic-related air pollution with coronary heart disease mortality. Am J Epidemiol 2012;175:898-906.

26. Evans J, van Donkelaar A, Martin RV, et al. Estimates of global mortality attributable to particulate air pollution using satellite imagery. Environ Res 2013;120:33-42.

27. Krewski D, Jerrett M, Burnett RT, et al. Extended follow-up and spatial analysis of the American Cancer Society study linking particulate air pollution and mortality. Res Rep Health Eff Inst 2009;140:5-114.

28. de Hartog JJ, Lanki T, Timonen KL, et al. Associations between PM2.5 and heart rate variability are modified by particle composition and beta-blocker use in patients with coronary heart disease. Environ Health Perspect 2009;117:105-11.

29. Folino AF, Scapellato ML, Canova $C$, et al. Individual exposure to particulate matter and the short-term arrhythmic and autonomic profiles in patients with myocardial infarction. Eur Heart $J$ 2009;30:1614-20.

30. Barclay JL, Miller BG, Dick S, et al. A panel study of air pollution in subjects with heart failure: negative results in treated patients. Occup Environ Med 2009;66:325-34.

31. Farrell TG, Bashir Y, Cripps T, et al. Risk stratification for arrhythmic events in postinfarction patients based on heart rate variability, ambulatory electrocardiographic variables and the signal-averaged electrocardiogram. J Am Coll Cardiol 1991;18:687-97.

32. Tsuji H, Larson MG, Venditti FJ, et al. Impact of reduced heart rate variability on risk for cardiac events. The Framingham Heart Study. Circulation 1996;94:2850-5.

33. Ohtsuka T, Hamada M, Hiasa G, et al. Effect of beta-blockers on circulating levels of inflammatory and anti-inflammatory cytokines in patients with dilated cardiomyopathy. J Am Coll Cardiol 2001;37:412-7.

34. Pekkanen J, Peters A, Hoek G, et al. Particulate air pollution and risk of ST-segment depression during repeated submaximal exercise tests among subjects with coronary heart disease: the Exposure and Risk Assessment for Fine and Ultrafine Particles in Ambient Air (ULTRA) study. Circulation 2002;106:933-8. 